\title{
Avaliação nutricional do milho com maior teor de óleo, nas formas de grãos secos e silagens, para suínos nas fases de crescimento e terminação ${ }^{1}$
}

\section{Marcos Augusto Alves da Silva ${ }^{2}$, Antonio Claudio Furlan ${ }^{3}$, Ivan Moreira ${ }^{3}$, Diovani Paiano ${ }^{2}$, Clóves Cabreira Jobim ${ }^{3}$, Livia Carla Grigoletto Barcellos ${ }^{4}$}

\author{
${ }^{1}$ Parte da dissertação de Mestrado do primeiro autor \\ 2 Doutorando do Programa de Pós-Graduação em Zootecnia - PPZ - UEM - Maringá-PR. \\ ${ }^{3}$ Departamento de Zootecnia da UEM - Maringá-PR. \\ ${ }^{4}$ Mestre pelo Programa de Pós-Graduação em Zootecnia - PPZ - UEM - Maringá-PR.
}

RESUMO - Dois experimentos foram conduzidos para determinação do valor nutritivo de rações contendo milho com maior teor de óleo, nas formas de grão seco (MSe), silagem de grãos úmidos (SGUM) e silagem de milho seco reidratado (SH) e avaliação do desempenho de suínos em crescimento e terminação alimentados com essas rações. No ensaio de digestibilidade foram utilizados 12 suínos mestiços, machos castrados, alojados em gaiolas e distribuídos em um delineamento experimental de parcelas subdivididas. Os valores de matéria seca (MSD), proteína (PD), amido (AMD), extrato etéreo (EED), matéria orgânica (MOD) e energia digestíveis (ED), bem como de energia metabolizável (EM), na matéria natural, para MSe, SGUM e SH, foram de 83,$42 ; 7,54 ; 63,90 ; 4,40 ; 82,28 \% ; 3.587$ e $3.513 \mathrm{kcal} / \mathrm{kg} ;$ de 60,$80 ; 4,85 ; 45,01 ; 3,10 ; 59,50 \% ; 2.647$ e 2.509 $\mathrm{kcal} / \mathrm{kg}$; de 66,$48 ; 6,16 ; 49,04 ; 3,41 ; 65,67 \% ; 2.853$ e $2.797 \mathrm{kcal} / \mathrm{kg}$, respectivamente. No experimento de desempenho, foram utilizados 32 suínos mestiços, distribuídos em um delineamento inteiramente casualizado, com quatro repetições e dois animais por unidade experimental. Os tratamentos consistiram de uma ração à base de milho e farelo de soja e de outras três, com substituição total do milho seco comum por MSe, SGUM e SH, com base nos valores de energia digestível. Não foram observadas diferenças entre os tratamentos na fase de crescimento. Na fase de terminação, houve aumento no consumo diário de ração e maior ganho diário de peso para a SGUM, em comparação à ração testemunha. Ocorreu redução no custo da ração por quilograma de peso vivo ganho para a SGUM em ambas as fases de crescimento. O MSe, a SGUM e a SH podem substituir totalmente o milho seco comum em rações para suínos nas fases de crescimento e terminação, sem prejudicar o desempenho. As rações contendo SGUM proporcionaram menores custos, em ração, por quilograma de animal produzido.

Palavras-chave: características de carcaça, desempenho, digestibilidade, valores energéticos

\section{Nutritional evaluation of dry grain and silage of higher oil corn on growing - finishing pigs feeding}

\begin{abstract}
Two experiments were carried out to determine nutritive value and verify performance of growing and finishing swine feed high moisture corn silage (HMCS) and reconstituted silage (RS) of higher oil corn. The digestibility assay was carried twelve cross breed barrow, were allotted in metabolism cages, in a completely randomized design. The values of digestible dry matter (DDM), digestible protein (DP), digestible starch (DS), digestible ether extract (DEE), digestible organic matter (DOM), digestible energy (DE) and metabolizable energy (ME) were for DG, HMCS and RS; 83.42, 7.54, 63.90, 4.40, $82.28 \% ; 3,587$ and 3,513 kcal/kg; 60.80, 4.85, 45.01, 3.10, 59.50\%; 2,647 and 2,509 kcal/kg; 66.48, 6.16, 49.04, 3.41, 65.67\%; 2,853 and $2,797 \mathrm{kcal} / \mathrm{kg}$, respectively, based on natural matter. In the performance experiment thirty-two cross breed swine were distributed in four treatments in a completely randomized design, with four experimental units and two pigs per experimental units. The treatments consisted of a basal corn and soybean meal diet and three diets with total replacement of common corn by DG, HMCS and RS higher oil corn based on the digestible energy. No differences were found among the treatments in the growing phase. In finishing phase, daily feed intake increased for the HMCS when compared with the control diet. The price of the diet per kilogram gain of body weight for the HMCS had decreased, in growing phase and finishing phase. It was concluded that the DG, HMCS and RS, could totally replace the common corn on growing and finishing diet, without impairing performance. Diets with high moisture corn silage resulted in smaller cost per kilogram of produced animal.
\end{abstract}

Key Words: carcass traits, digestibility, energy values, performance 


\section{Introdução}

A alimentação representa de 70 a $80 \%$ dos custos na produção de suínos. O milho seco moído consiste, atualmente, na principal fonte energética, sendo responsável pela maior parte dos custos com a produção de rações. Uma preocupação constante dos pesquisadores tem sido a busca por alimentos que possam otimizar os índices produtivos e econômicos nos sistemas de exploração pecuários, sem comprometer, no entanto, o desempenho animal.

As variedades de milho utilizadas na alimentação de suínos contêm, em média, 3,5\% de EE. Atualmente, é possível encontrar no mercado novos híbridos de milho, desenvolvidos com o melhoramento e a manipulação genética, apresentando, assim, perfil nutricional mais adequado à alimentação animal. O milho com maior teor de óleo, por exemplo, pode apresentar de 5 a $8,5 \%$ de EE, o que eleva o valor da energia, permitindo formular rações com maior densidade energética e melhorar o desempenho e as características de carcaça dos animais (Adams \& Jensen, 1987; Han \& Parsons, 1987).

Entretanto, o uso do milho em forma de silagem de grãos úmidos em rações para suínos tem sido uma alternativa para a produção de grãos, com várias vantagens em relação ao milho seco: ausência de taxas e impostos sobre o produto, ausência de perdas econômicas com transporte, frete e desconto sobre a umidade, menor custo de armazenamento, antecipação do período de colheita e menores perdas por ataques de roedores e insetos (Keplin, 2000).

De acordo com Lima et al. (1998), a fermentação anaeróbia propicia um produto com maior disponibilidade de energia para suínos que o milho seco. Além disso, é provável que, durante o processo fermentativo no interior do silo, ocorra gelatinização parcial do amido e que a ação das enzimas digestivas seja mais eficiente nas partículas úmidas de silagem.

Segundo Lopes (2000), o valor nutritivo e os efeitos da utilização do milho na forma de silagem de grãos úmidos sobre o desempenho de suínos sejam semelhantes ou melhores que os obtidos com o milho seco.

Com a melhoria da qualidade nutricional do grão de milho e com a utilização da silagem de grãos úmidos de milho, a literatura nacional carece de estudos científicos para conferir maior suporte aos resultados em condições brasileiras. Assim, o objetivo neste trabalho foi avaliar, por meio de ensaio de digestibilidade e experimento de desempenho, o uso do milho com maior teor de óleo, nas formas de grão seco e silagens, para suínos nas fases de crescimento e terminação.

\section{Material e Métodos}

Dois experimentos foram conduzidos no setor de suinocultura da Fazenda Experimental da Universidade Estadual de Maringá. No ensaio de digestibilidade, foram utilizados 12 suínos mestiços (Landracex Large-Whitex Duroc), machos, castrados, com $39,6 \pm 3,3 \mathrm{~kg}$ de peso vivo inicial, distribuídos em um delineamento experimental de parcelas subdivididas, totalizando quatro tratamentos e seis repetições, em que a unidade experimental foi constituída por um suíno.

Os animais foram alojados em gaiolas para estudos de metabolismo semelhantes às descritas por Pekas (1968). O período experimental constou de cinco dias de adaptação às rações experimentais e às gaiolas, seguidos por dois períodos de coletas de fezes e urina (cinco dias cada um) com intervalo de um dia entre períodos. Foi utilizado o método de coleta total de fezes, com a adição de $2 \%$ de óxido de ferro $\left(\mathrm{Fe}_{2} \mathrm{O}_{3}\right)$ às rações como marcador do início e do fim da coleta de fezes.

O alimento avaliado foi o milho com maior teor de óleo, nas formas de grão seco (MSe), silagem de grãos úmidos (SGUM) e silagem de milho seco reidratado (SH), que substituíram, com base na matéria seca, 30\% da raçãoreferência (RR), resultando em três rações-teste (RT). As rações contendo as silagens foram misturadas diariamente.

A variedade de milho (Zea mays) utilizada foi a DAS 766. A colheita do milho para a SGUM foi realizada em março de 2002, quando os grãos de milho apresentavam-se no estádio farináceo e com teor de umidade de $34,20 \%$. A colheita foi feita por colhedeira mecânica e os grãos foram triturados em moinho do tipo martelo, utilizando-se peneira de $10 \mathrm{~mm}$ e, em seguida, ensilados em manilhas de concreto com capacidade para $1.000 \mathrm{~L}$.

O MSe e os grãos para o preparo da SH foram colhidos quando atingiram $88 \%$ de MS. Os grãos foram triturados em moinho do tipo martelo, utilizando-se peneira de $10 \mathrm{~mm}$ e, em seguida, foi adicionada água, para obtenção de um alimento com $30 \%$ de umidade. Posteriormente, foram ensilados em tambores de polietileno com capacidade para $200 \mathrm{~L}$.

A ração-referência, à base de milho e farelo de soja, foi formulada de acordo com a composição química e os valores energéticos dos ingredientes indicados por Rostagno et al. (2000).

As rações foram fornecidas em duas alimentações diárias: $55 \%$ às $8 \mathrm{~h}$ e $45 \%$ às $16 \mathrm{~h}$. A quantidade total diária foi estabelecida conforme o consumo na fase de adaptação, com base no peso metabólico $\left(\mathrm{kg}^{0,75}\right)$ de cada unidade experimental, tendo como consumo metabólico a média de $97,89 \mathrm{~g} / \mathrm{UPM}$. No segundo período de coleta, o fornecimento de ração foi aumentado em $8 \%$ para todos os animais. 
Após cada refeição, foi fornecida água no comedouro, na proporção de $3,0 \mathrm{~mL} / \mathrm{g}$ de ração, calculada para cada unidade experimental, para evitar o excesso de consumo de água.

As fezes totais produzidas foram coletadas uma vez ao dia em sacos plásticos e armazenadas em congelador a $-18^{\circ} \mathrm{C}$. Posteriormente, foram homogeneizadas e uma amostra de $20 \%$ foi retirada, seca em estufa de ventilação forçada $\left(55^{\circ} \mathrm{C}\right)$ e moída para análises posteriores.

Diariamente, a urina foi coletada em baldes plásticos contendo $20 \mathrm{~mL}$ de $\mathrm{HCl}$ 1:1 e uma alíquota de $20 \%$ foi acumulada e congelada a $-18^{\circ} \mathrm{C}$. Posteriormente, essas alíquotas foram homogeneizadas e amostradas para determinação dos níveis de energia.

As análises dos alimentos, das fezes e da urina foram realizadas segundo procedimentos descritos por Silva \& Queiroz (2002). As determinações de amido dos alimentos e das fezes foram feitas de acordo com o método enzimático proposto por Poore et al. (1989), adaptado por Pereira \& Rossi (1995). Os valores do pH dos alimentos e das rações foram determinados pelo método utilizado por Phillip \& Fellner (1992). As análises de granulometria das silagens foram realizadas conforme a metodologia descrita por Zanotto \& Bellaver (1996).

Os coeficientes de digestibilidade da matéria seca (CDMS), da proteína bruta (CDPB), do amido (CDAM), do extrato etéreo (CDEE), da matéria orgânica (CDMO) e da energia bruta (CDEB) e o coeficiente de metabolização da energia bruta (CMEB) dos alimentos foram calculados pelo método de coleta total de fezes e urina, segundo Moreira et al. (1994), e analisados de acordo com o modelo estatístico:

$$
\mathrm{Y}_{i j k}=\mathrm{m}+\mathrm{T}_{i}+\mathrm{P}_{\mathrm{j}}+\mathrm{A}_{\mathrm{k}} / \mathrm{T}_{\mathrm{i}}+\mathrm{e}_{i j k}
$$

em que $\mathrm{Y}_{i j k}=$ coeficientes de digestibilidade aparente da MS, da PB, do amido, do EE, da MO e da EB e o coeficiente de metabolização da EB observado na unidade experimental $k$, recebendo o alimento $i$, no período $j ; \mathrm{m}=$ constante geral; $\mathrm{T}_{i}=$ efeito do tipo do alimento $i$, sendo $i=1 ; 2 ; 3(1=$ MSe; $2=\mathrm{SGUM}$ e $3=\mathrm{SH}) ; \mathrm{A}_{\mathrm{k}} / \mathrm{T}_{\mathrm{i}}=$ efeito do animal $K$ dentro do tratamento $i ; \mathrm{P}_{\mathrm{j}}=$ efeito do período; $\mathrm{e}_{i j k}=$ erro aleatório associado a cada observação $\mathrm{Y}_{i j k}$.

Os teores de matéria seca (MSD), proteína (PD), amido (AMD), extrato etéreo (EED), matéria orgânica (MOD) e energia digestíveis (ED), bem como de energia metabolizável (EM) dos alimentos foram calculados utilizando-se a fórmula de Matterson et al. (1965).

No experimento de desempenho, foram utilizados 32 suínos mestiços (Landrace, Large-White e Duroc), metade machos castrados e metade fêmeas, com peso inicial de $29,4 \pm 4,2 \mathrm{~kg}$, distribuídos em um delineamento de blocos casualizados, com quatro tratamentos, quatro repetições, e dois animais por unidade experimental (um macho e uma fêmea). As pesagens dos animais foram realizadas no início e no final de cada fase.

Os animais foram alojados em galpões de alvenaria cobertos com telhas de fibrocimento, divididos em duas alas, cada uma composta por dez baias $\left(7,60 \mathrm{~m}^{2}\right.$ cada), separadas por um corredor central. Cada baia possuía bebedouros tipo chupeta no fundo e um comedouro semiautomático de duas bocas na parte frontal, de modo a proporcionar livre acesso à ração e à água. As baias apresentavam ao fundo uma lâmina d'água $\mathrm{de} \pm 8 \mathrm{~cm}$ de profundidade, a qual era lavada e renovada duas vezes por semana.

O MSe, a SGUM e a SH avaliados no ensaio de digestibilidade apresentaram, respectivamente, 3.587, 2.647 e $2.853 \mathrm{kcal} \mathrm{ED} / \mathrm{kg}$ na matéria natural. As composições em aminoácidos do MSe, SGUM e o SH foram calculadas de acordo com os teores de PB (8,78\% para MSe; 5,78\% para SGUM e 6,92\% para SH) e a concentração de aminoácidos do milho seco comum apresentada nas tabelas da EMBRAPA (1991). A composição em nutrientes do milho seco comum, do farelo de soja, do calcário e do fosfato bicálcico utilizados nas rações foi obtida das tabelas da EMBRAPA (1991).

Os tratamentos experimentais consistiram de quatro rações isoenergéticas, isocálcicas e isoaminoacídicas para lisina. Foi utilizada uma ração-referência (RR) contendo milho seco comum e outras três nas quais o milho seco comum foi totalmente substituído por MSe, SGUM e SH, com base nos valores energéticos, convertidos para $87,45 \%$ de matéria seca. As rações foram formuladas para atender às exigências nutricionais descritas por Rostagno et al. (2000) para as fases de crescimento $(29,4-56,0 \mathrm{~kg})$ e terminação $(56,0-87,4 \mathrm{~kg})$ (Tabela 1$)$.

As rações contendo SGUM e SH foram misturadas diariamente a um concentrado, composto pelos demais ingredientes, previamente preparados. As rações foram pesadas diariamente e fornecidas na forma farelada. A água e as rações foram fornecidas à vontade.

Os valores de $\mathrm{pH}$ das silagens foram obtidos conforme os procedimentos utilizados por Phillip \& Fellner(1992). As análises de granulometria das silagens foram realizadas de acordo com a metodologia proposta por Zanotto \& Bellaver (1996).

Ao final do período experimental, foram abatidos 16 animais, quatro por tratamento (dois machos e duas fêmeas), para determinação das características de carcaça de acordo com o "Método Brasileiro de Classificação de Carcaças" (ABCS, 1973).

O preço da SGUM foi ajustado para a mesma base de MS do milho seco $(87,45 \%)$ e a estimativa foi feita considerando os custos de produção, que envolveram os gastos com plantio, colheita, transporte e ensilagem (trituração e 
Tabela 1 - Composições percentual e química das rações experimentais para suínos nas fases de crescimento e terminação Table 1 - Ingredient and chemical and compositions of the experimental diets for growing and finishing swine

\begin{tabular}{|c|c|c|c|c|c|c|c|c|}
\hline \multirow{2}{*}{$\begin{array}{l}\text { Ingrediente } \\
\text { Ingredient }\end{array}$} & \multicolumn{4}{|c|}{$\begin{array}{c}\text { Crescimento } \\
\text { Growing }\end{array}$} & \multicolumn{4}{|c|}{$\begin{array}{c}\text { Terminação } \\
\text { Finishing }\end{array}$} \\
\hline & $\mathrm{RT}$ & MSe & SGUM & $\mathrm{SH}$ & R T & MSe & SGUM & $\mathrm{SH}$ \\
\hline Milho grão ${ }^{1}$ (Corn grain) & 67,08 & - & - & - & 71,61 & - & - & - \\
\hline Grão $\operatorname{seco}^{2}$ (Dry grain) & - & 68,48 & - & - & - & 73,09 & - & - \\
\hline SGUM (HMCS) & - & - & $66,95 \quad(88,98$ & - & - & - & $71,47(94,98)^{3}$ & - \\
\hline Óleo soja (Soybean oil) & 1,52 & - & 0,68 & 0,53 & 1,62 & - & 0,72 & 0,56 \\
\hline Fosfato bicálcico (Dicalc. phosp.) & 1,37 & 1,33 & 1,33 & 1,35 & 1,19 & 1,14 & 1,14 & 1,17 \\
\hline Calcário (Limestone) & 0,81 & 0,86 & 0,85 & 0,84 & 0,68 & 0,74 & 0,73 & 0,71 \\
\hline Sal comum (Salt) & 0,40 & 0,40 & 0,40 & 0,40 & 0,40 & 0,40 & 0,40 & 0,40 \\
\hline Tylan S-100 (Tylan S-100) & 0,10 & 0,10 & 0,10 & 0,10 & 0,10 & 0,10 & 0,10 & 0,10 \\
\hline Supl. vit. $\min ^{4}{ }^{\text {(Min. vit. suppl.) }}$ & 0,50 & 0,50 & 0,50 & 0,50 & 0,40 & 0,40 & 0,40 & 0,40 \\
\hline $\mathrm{ED}, \mathrm{kcal} / \mathrm{kg}(D E, \mathrm{kcal} / \mathrm{kg})$ & 3.426 & 3.426 & 3.426 & 3.426 & 3.444 & 3.444 & 3.444 & 3.444 \\
\hline $\mathrm{PB}, \%(C P, \%)$ & 18,60 & 18,91 & 18,47 & 18,84 & 17,06 & 17,40 & 16,93 & 17,32 \\
\hline Lis \% (Lys, \%) & 0,95 & 0,95 & 0,95 & 0,95 & 0,85 & 0,85 & 0,85 & 0,85 \\
\hline Met+Cis, $\%($ Met + Cys, \%) & 0,61 & 0,61 & 0,58 & 0,60 & 0,57 & 0,57 & 0,55 & 0,57 \\
\hline $\mathrm{Ca}, \%$ & 0,76 & 0,76 & 0,76 & 0,76 & 0,65 & 0,65 & 0,65 & 0,65 \\
\hline $\mathrm{P}, \%$ & 0,58 & 0,60 & 0,59 & 0,59 & 0,53 & 0,55 & 0,54 & 0,54 \\
\hline \multicolumn{9}{|c|}{ 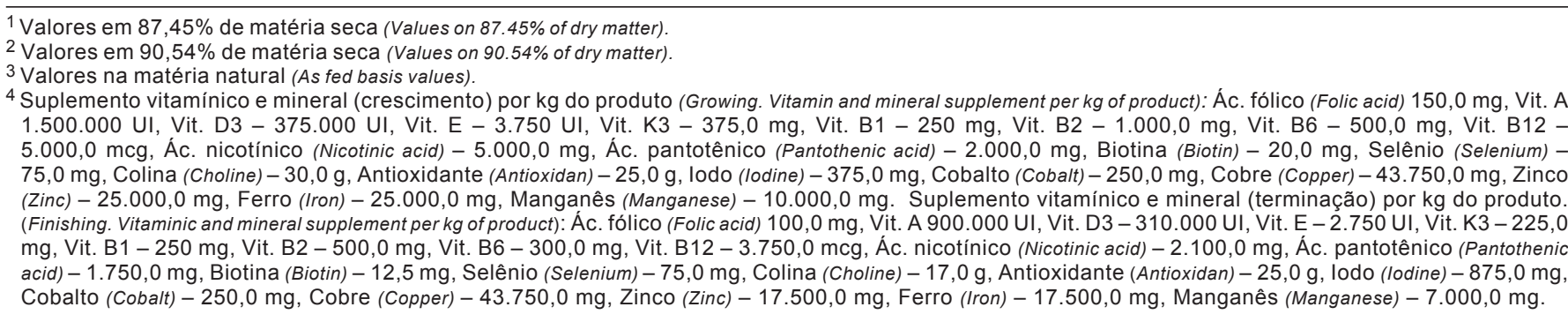 } \\
\hline
\end{tabular}

compactação) da SGUM com produtividade média de $6.000 \mathrm{~kg} / \mathrm{ha}$ (produtividade média da região).

Para verificar a viabilidade econômica da substituição do milho seco comum pelo milho com maior teor de óleo (nas formas de grão seco e silagens) nas rações, foi determinado inicialmente o custo de ração por quilograma de peso vivo ganho (Yi), segundo Bellaver et al. (1985). Em seguida, foram calculados o Índice de Eficiência Econômica (IEE) e o Índice de Custo (IC), proposto por Gomes et al. (1991).

Os dados de desempenho e de carcaça e as variáveis econômicas foram submetidos à análise de variância, pelo programa Sistema de Análises Estatísticas e Genéticas SAEG(UNIVERSIDADEFEDERALDEVIÇOSA, 1997). Para comparação dos resultados obtidos entre os tratamentos, utilizou-se o teste Tukey a 5\%.

\section{Resultados e Discussão}

Os teores de PB eEB da SGUM(Tabela2), convertidos para mesma base de MS do milho seco comum, conforme a tabela da
EMBRAPA (1991), foram inferiores aos encontrados na literatura, enquanto os teores de $\mathrm{EE}, \mathrm{Ca}$ e $\mathrm{P}$ foram superiores. Constam na tabela da EMBRAPA (1991) valores de 8,31\% de PB; $3,86 \%$ de EE; $4.007 \mathrm{kcal} / \mathrm{kg}$ de EB; $0,01 \%$ de Cae $0,23 \%$ de Pt para a silagem de grãos de milho, quando corrigidos para $87,45 \%$ deMS.

O milho avaliado, na forma de grão seco, apresentou teor de óleo $28,45 \%$ superior ao milho seco comum quando convertido para mesma base de MS e comparado ao valor descrito nas tabelas de Rostagno (2000).

Essas variações nos teores dos nutrientes entre os milhos podem ser atribuídas a diversos outros fatores, como o potencial genético das sementes para esse atributo, o nível de adubação utilizado (especialmente $\mathrm{N}$ ), a fertilidade do solo e as condições climáticas (Lima et al., 1998).

Os valores de $\mathrm{pH}$ das silagens do milho com maior teor de óleo, de 3,98 para a SGUM e 3,96 para a SH, podem ser considerados satisfatórios por estarem próximos aos citados por Jobim et al. (1997) e Lima et al. (1998), de 3,6 e 4,0, respectivamente, para silagens de grãos úmidos de milho. 
Tabela 2 - Teores de matéria seca, proteína bruta, amido, matéria orgânica, extrato etéreo, cinzas, cálcio, fósforo total e energia bruta, valor de $\mathrm{pH}$ e diâmetro geométrico médio (DGM) das partículas dos alimentos avaliados (MSe, SGUM e SH), na matéria natural (MN) e em $87,45 \%$ de matéria seca (MS)

Table 2 - Contents of dry matter, crude protein, starch, organic matter, ether extract, , ash, calcium, total phosphorus, gross energy, value of pH and medium geometric diameter (MGD) of particles of evaluated food (DG, HMCS and RS) ${ }^{1}$, as fed basis (FB) and $87.45 \%$ of dry matter basis (DM)

\begin{tabular}{|c|c|c|c|c|c|c|}
\hline \multirow[b]{2}{*}{$\begin{array}{l}\text { Parâmetro } \\
\text { Parameter }\end{array}$} & \multicolumn{3}{|c|}{$\begin{array}{c}\text { Valores com base na MN } \\
\text { Value with basis } F B\end{array}$} & \multicolumn{3}{|c|}{$\begin{array}{c}\text { Valores com base em } 87,45 \% \text { de MS } \\
\text { Value with } 87.45 \% \text { of basis (DM) }\end{array}$} \\
\hline & $\mathrm{MSe}^{1}$ & $\mathrm{SGUM}^{1}$ & $\mathrm{SH}^{1}$ & $\mathrm{MSe}^{2}$ & SGUM $^{2}$ & $\mathrm{SH}^{2}$ \\
\hline Matéria seca, \% (Dry matter, \%) & 90,54 & 65,80 & 70,72 & 87,45 & 87,45 & 87,45 \\
\hline Proteína bruta, \% (Crude protein, \%) & 8,78 & 5,78 & 6,92 & 8,48 & 7,68 & 8,56 \\
\hline Amido, \% (Starch, \%) & 64,01 & 45,08 & 49,01 & 61,82 & 59,91 & 60,61 \\
\hline Matéria orgânica, \% (Organic matter, \%) & 88,87 & 64,69 & 69,79 & 85,84 & 85,97 & 86,30 \\
\hline Extrato etéreo, \% (Ether extract, \%) & 5,03 & 3,60 & 3,75 & 4,85 & 4,78 & 4,63 \\
\hline Cinzas, \% (Ash, \%) & 1,67 & 1,11 & 0,93 & 1,61 & 1,48 & 1,15 \\
\hline Cálcio, \% (Calcium, \%) & 0,016 & 0,013 & 0,016 & 0,015 & 0,017 & 0,020 \\
\hline Fósforo total, \% (Phosphorus, \%) & 0,27 & 0,194 & 0,200 & 0,260 & 0,253 & 0,248 \\
\hline Energia bruta, $\mathrm{kcal} / \mathrm{kg}$ (Gross energy, kcal/kg) & 3.991 & 2.893 & 3.128 & 3.855 & 3.844 & 3.868 \\
\hline $\mathrm{pH}$ & 6,09 & 3,98 & 3,96 & - & - & - \\
\hline DGM, mm $(M G M, m m)$ & 727 & 967 & 900 & - & - & - \\
\hline
\end{tabular}

\footnotetext{
1 Valores na matéria natural (As-fed basis values).

${ }^{2}$ Valores convertidos para $87,45 \%$ de MS conforme os dados constantes na tabela da EMBRAPA (1991) para o milho seco comum (grão) (Values converted for $87.45 \%$ of dry matter basis, according to Embrapa [1991] tables for corn grain).
}

Não foram observadas diferenças $(\mathrm{P}>0,05)$ nos coeficientes de digestibilidade aparente da MS, da PB, do amido, do EE, da MO e da EB e nos coeficientes de metabolização da EB entre os três alimentos avaliados (Tabela 3).

Os CDEB e CDPB obtidos para a SGUM e SH neste experimento foram inferiores aos descritos nas Tabelas da EMBRAPA (1991) para silagem de grãos de milho comum (95,20 e 95,82\%, respectivamente). Entretanto, os CDEB, CMEB e CDPB obtidos para as silagens foram bastante semelhantes aos reportados por Oliveira (2002) para a silagem de grãos úmidos de milho comum $(90,91 \%$ para CDEB; 88,54\% para CMEB e 87,82\% para CDPB) e Lima et al. (1998), que, trabalhando com duas silagens de grãos úmidos de milho comum produzidas sob as mesmas recomendações técnicas, mas em propriedades diferentes, obtiveram 90,76 e 91,01\% para CDEB; 87,62 e 88,08\% para CMEB e 83,01 e $85,68 \%$ para CDPB.

Quando comparados os CDEB, CMEB e CDPB da SGUM e SH aos descritos nas tabelas de Rostagno et al. (2000) para o milho seco comum $(88,38 \%$ para CDEB; $84,69 \%$ para CMEB e $82,96 \%$ para CDPB), constatou-se que as silagens produzidas com milho com maior teor de óleo apresentaram maior disponibilidade desses nutrientes, evidenciando que o processo de ensilagem melhora o valor nutricional do milho.

Comparando os CDEB e o CMEB do MSe aos apresentados nas tabelas da EMBRAPA (1991) e Rostagno et al. (2000), para o milho seco comum $(87,59$ e $88,38 \%$ para CDEB e 83,37 e $84,69 \%$ para CMEB, respectivamente), observou-se que o milho seco com maior teor de óleo apresentou melhor disponibilidade da energia, provavelmente em razão da maior porcentagem de gordura no grão do MSe.

A digestibilidade do amido dos três alimentos avaliados foi considerada total, corroborando os relatos de Holmes et al. (1973) de que a concentração de amido nas fezes $(10 \mathrm{~g} / \mathrm{kg})$ representou menos de $0,2 \%$ do amido ingerido, diminuindo a acurácia da mensuração e assumindo-se, assim, uma digestão completa do amido em ambas as dietas contendo milho seco ou úmido. A maior digestibilidade do amido dos grãos ensilados deve-se, sobretudo, à fragilização da matriz protéica que recobre os grãos de amido da endosperma periférica (Demarquilly \& Andrieu, 1996, citado por Jobim et al., 2001), que ocorre por ação dos ácidos da silagem sobre o amido, pois, segundo Rooney \& Pflugfelder (1986), o amido pode ser gelatinizado pela ação de agentes químicos.

Os CDMS da SGUM e SH foram comparativamente superiores ao coeficiente de $80,92 \%$, obtido por Oliveira (2002), que trabalhou com animais de peso vivo inicial menor (16,31 kg) e com silagem de grãos úmidos de milho comum de diâmetro geométrico médio (DGM) superior $(1.501 \mathrm{~mm})$ ao deste trabalho. A maior digestibilidade da MS talvez possa estar relacionada ao menor DGM das partículas de milho com maior teor de óleo das silagens, resultando em menores partículas de pericarpo e diminuindo sua resistência à degradação microbiana e à digestão enzimática no intestino delgado (Jobim et al., 2001).

De acordo com Jongbloed et al. (2000), a melhora no desempenho animal, assim como na digestibilidade da MS, 
Tabela 3 - Coeficientes de digestibilidade aparente da matéria seca (CDMS), da proteína bruta (CDPB), do amido (CDAM), do extrato etéreo (CDEE), da matéria orgânica (CDMO) e da energia bruta (CDEB) e coeficiente de metabolização da energia bruta (CMEB) dos alimentos avaliados

Table 3 - Dry mater $(D M D C)$, crude protein (CPDC), starch (SDC), ether extract (EEDC), organic matter (OMDC), gross energy (GEDC) apparent digestibility coefficients and gross energy metabolization coefficient (GEMC) of evaluated food

\begin{tabular}{lcccc}
\hline Parâmetro & MSe & SGUM & SH & CV, \% \\
Parameter & $D G$ & $H M C S$ & $R S$ & \\
\hline CDMS, \% DMDC, \% & 92,13 & 92,40 & 94,00 & 2,07 \\
CDPB, \% CPDC, \% & 85,86 & 83,91 & 89,09 & 5,80 \\
CDAM, \% SDC, \% & 100 & 100 & 100 & 0,19 \\
CDEE, \% EEDC, \% & 87,33 & 86,06 & 90,99 & 7,77 \\
CDMO, \% OMDC, \% & 92,57 & 91,98 & 94,10 & 1,93 \\
CDEB, \% GEDC, \% & 89,88 & 91,51 & 91,19 & 1,99 \\
CMEB, \% GEDM, \% & 88,02 & 88,34 & 89,43 & 2,17 \\
\hline
\end{tabular}

${ }^{1}$ Coeficiente de variação (Coefficient of variation).

da MO, das cinzas, do cálcio e do fósforo, provavelmente seja decorrente do fato de ácidos orgânicos diminuírem o pH do alimento no trato gastrointestinal, que resulta em maior dissociação dos compostos minerais da dieta, o que proporciona a formação de complexos minerais quelatados, melhora a sanidade do intestino dos animais e reduz a taxa de esvaziamento gástrico.

Com o atraso no esvaziamento estomacal, é possível que as enzimas digestivas, assim como a amilase salivar (Holmes et al., 1974), a pepsina e a lipase gástrica (Solomon, 1994), possam agir por mais tempo. Além disso, provavelmente a ação das enzimas digestivas seja mais eficiente nas partículas úmidas de milho (Holmes et al., 1973).

Holmes et al. (1973) constataram maiores coeficientes de digestibilidade ileal e total da matéria seca, energia e proteína para as dietas contendo milho úmido tratado com ácidos orgânicos ou silagem de grãos úmidos de milho, cujo $\mathrm{pH}$ variava entre 4,77 e 5,16, em comparação à dieta com milho seco comum ( $\mathrm{pH}=5,35)$. Conseqüentemente, menor quantidade de nutrientes (amido e compostos nitrogenados) foi fermentada no intestino grosso, o qual é menos eficiente em prover aminoácidos e energia do substrato para o animal.

Para comparação dos dados obtidos (Tabela 4) com os da literatura, os teores de nutrientes digestíveis determinados neste trabalho e os de outros autores foram convertidos para $87,45 \%$ de MS, com base na matéria seca do milho seco comum, de acordo com a tabela da EMBRAPA (1991).

Os teores de MSD, PD, ED e EM dos alimentos avaliados foram maiores que os respectivos teores de 70,76\%; $5,48 \%, 3.471 \mathrm{kcal} / \mathrm{kg} \mathrm{e} 3.381 \mathrm{kcal} / \mathrm{kg}$ encontrados por Oliveira (2002), para a silagem de grãos úmidos de milho comum, à exceção do valor da ED do MSe, que se apresentou valor bastante próximo.

Os teores de ED do MSe, SGUM e SH foram menores que o determinado pela EMBRAPA (1991), para a silagem de grãos úmidos de milho, e por Lima et al. (1998), para duas silagens de grãos úmidos de milho comum, quando convertidos para o mesmo teor de MS. Os teores de PD e EM foram inferiores aos de $7,96 \%$ e $3.550 \mathrm{kcal} / \mathrm{kg}$ da silagem de grãos úmidos de milho comum descritos na tabela da EMBRAPA(1991).

Os valores de PD, ED e EM dos alimentos avaliados foram bastante próximos aos das tabelas da EMBRAPA (1991), de 7,51\%, $3.460 \mathrm{kcal} / \mathrm{kg}$ e $3.293 \mathrm{kcal} / \mathrm{kg}$, e de Rostagno (2000), de 7,14\%, $3.490 \mathrm{kcal} / \mathrm{kg}$ e $3.344 \mathrm{kcal} / \mathrm{kg}$, para o milho seco comum, à exceção do valor da PD da SGUM, que foi inferior.

O milho com maior teor de óleo, na forma de grão seco, apresentou $62 \mathrm{kcal} \mathrm{de} \mathrm{EM} / \mathrm{kg}$ a mais que o milho seco comum apresentado nas tabelas de Rostagno (2000). Este acréscimo de EM deve-se ao maior teor de óleo, de 1,38\%, ou seja, $28,45 \%$ a mais para o milho avaliado. Resultados semelhantes foram encontrados por Lima et al. ( 2001).

Ao comparar os teores de EM das silagens SGUM e SH com o MSe, verifica-se superioridade média das silagens em $58 \mathrm{kcal} / \mathrm{kg}$.

$\mathrm{O}$ dados referentes ao $\mathrm{CDR}$, ao GDP e à $\mathrm{CA}$ nas fases de crescimento e terminação encontram-se na Tabela 5. A substituição total do milho seco comum pelo MSe, pela SGUM e SH nas rações não provocou diferenças $(\mathrm{P}>0,05)$ no CDR, GDP e CA durante a fase de crescimento. Lopes et al. (1999), trabalhando com substituição, na matéria seca, de todo o milho comum da ração por silagem de grãos úmidos de milho comum, também não observaram diferenças no CDR, GDP e CA na fase de crescimento. A mesma resposta foi encontrada por Lima et al. (2003), em suínos em crescimento e terminação alimentados com ração em que o milho comum foi totalmente substituído por milho seco com maior teor de óleo.

Engelke et al. (1984) constataram maior consumo de ração nas fases de crescimento e terminação, quando o milho comum da dieta foi fornecido na forma de silagem de grãos úmidos. Duduk (1988) verificou maior ganho de peso e melhor CA nos animais em crescimento alimentados com rações contendo silagem de grãos úmidos de milho, em comparação àqueles submetidos a dietas à base de milho comum.

A ausência de diferenças quando da substituição total do milho seco comum pelo milho com maior teor de óleo nas formas de MSe, SGUM e SH era esperada, pois todas as 
Tabela 4 - Teores de matéria seca (MSD), proteína (PD), amido (AMD), extrato etéreo digestível (EED), matéria orgânica (MOD) e energia digestíveis (ED), bem como de energia metabolizável (EM), do MSe, SGUM e SH, na matéria natural (MN) e em 87,45\% de matéria seca (MS)

Table 4 - Contents of digestible dry matter (DDM), digestible protein (DP), digestible starch (DS), digestible ether extract (DEE), organic matter (OMD), digestible energy (DE) and metabolizable energy (ME) of DG, HMCS and RS, as fed basis(FB) and in $87.45 \%$ of dry matter (DM)

\begin{tabular}{|c|c|c|c|c|c|c|}
\hline \multirow[b]{2}{*}{$\begin{array}{l}\text { Nutriente } \\
\text { Nutrient }\end{array}$} & \multicolumn{3}{|c|}{$\begin{array}{c}\text { Valores com base na } \mathrm{MN} \\
\text { Value with basis } F B\end{array}$} & \multicolumn{3}{|c|}{$\begin{array}{c}\text { Valores com base em } 87,45 \% \text { de MS } \\
\text { Value with } 87.45 \% \text { of basis (DM) }\end{array}$} \\
\hline & $\begin{array}{c}\mathrm{MSe}^{1} \\
D G\end{array}$ & $\begin{array}{c}\text { SGUM }^{1} \\
H M C S\end{array}$ & $\begin{array}{c}\mathrm{SH}^{1} \\
R S\end{array}$ & $\begin{array}{c}\mathrm{MSe}^{2} \\
D G\end{array}$ & $\begin{array}{l}\mathrm{SGUM}^{2} \\
H M C S\end{array}$ & $\begin{array}{c}\mathrm{SH}^{2} \\
R S\end{array}$ \\
\hline MSD, \% (DDM, \%) & 83,42 & 60,80 & 66,48 & 80,56 & 80,80 & 82,21 \\
\hline $\mathrm{PD}, \%(D P, \%)$ & 7,54 & 4,85 & 6,16 & 7,28 & 6,44 & 7,62 \\
\hline $\mathrm{AMD}, \%(D S, \%)$ & 63,90 & 45,01 & 49,04 & 61,72 & 59,81 & 60,65 \\
\hline EED, \% (DEE, \%) & 4,40 & 3,10 & 3,41 & 4,25 & 4,11 & 4,22 \\
\hline MOD, \% (OMD, \%) & 82,28 & 59,50 & 65,67 & 79,46 & 79,08 & 81,21 \\
\hline $\mathrm{ED}, \mathrm{kcal} / \mathrm{kg}(D E, \mathrm{kcal} / \mathrm{kg})$ & 3.587 & 2.647 & 2.853 & 3.464 & 3.518 & 3.528 \\
\hline $\mathrm{EM}, \mathrm{kcal} / \mathrm{kg}(M E, \mathrm{kcal} / \mathrm{kg})$ & 3.513 & 2.590 & 2.797 & 3.393 & 3.442 & 3.459 \\
\hline
\end{tabular}

1 Valores na matéria natural (As fed basis values).

2 Valores convertidos para $87,45 \%$ de matéria seca conforme dados constantes na tabela da EMBRAPA (1991) para o milho seco comum (grão) (Values converted for $87.45 \%$ of dry matter basis according data presents by table of EMBRAPA (1991) for common corn grain)

Tabela 5 - Consumo diário de ração (CDR), ganho diário de peso (GDP) e conversão alimentar (CA) de suínos nas fases de crescimento e terminação, alimentados com rações contendo milho comum e milho com maior teor de óleo, nas formas de grão seco e silagens

Table 5 - Daily feed intake (DFI), daily weight gain (DWG) and feed:gain ration $(F: G)$ of growing and finishing pigs fed diets containing corn, dry grain and silage of higher oil corn

\begin{tabular}{|c|c|c|c|c|c|}
\hline \multirow{3}{*}{$\begin{array}{l}\text { Variável } \\
\text { Variable }\end{array}$} & \multicolumn{4}{|c|}{$\begin{array}{l}\text { Tratamento } \\
\text { Treatment }\end{array}$} & \multirow{3}{*}{$\mathrm{CV}^{1}$} \\
\hline & $\mathrm{RT}$ & MSe & SGUM & SH & \\
\hline & $C D$ & $D G$ & $H M C S$ & $R S$ & \\
\hline & \multicolumn{4}{|c|}{ Crescimento (Growing) } & \\
\hline $\begin{array}{l}\text { CDR, } \mathrm{kg} / \mathrm{dia} \\
D F I, \mathrm{~kg} / \text { day }\end{array}$ & 1,97 & 2,04 & 1,95 & 2,03 & 5,92 \\
\hline $\begin{array}{l}\text { GDP, } \mathrm{kg} / \mathrm{dia} \\
D W G, \mathrm{~kg} / \text { day }\end{array}$ & 0,87 & 0,88 & 0,89 & 0,91 & 5,90 \\
\hline $\mathrm{CA}$ & 2,26 & 2,30 & 2,20 & 2,21 & 5,11 \\
\hline
\end{tabular}

Terminação (Finishing)

\begin{tabular}{|c|c|c|c|c|}
\hline CDR, kg/dia & $2,44^{b}$ & $2,65^{\mathrm{ab}}$ & $2,79^{a}$ & $2,63^{\mathrm{ab}}$ \\
\hline $\begin{array}{l}D F 1, \mathrm{~kg} / \mathrm{day} \\
\mathrm{GDP}, \mathrm{kg} / \mathrm{dia}\end{array}$ & $0,90^{\mathrm{b}}$ & $0,94^{\mathrm{ab}}$ & $1,01^{\mathrm{a}}$ & $0,95^{\mathrm{ab}}$ \\
\hline $\begin{array}{l}D W G, k g / d a y \\
\mathrm{CA}\end{array}$ & 2,71 & 2,81 & 2,77 & 2,75 \\
\hline
\end{tabular}

Médias na mesma linha seguidas por letras distintas são diferentes $(P<0,05)$ (Means in a row followed by different letter differ, $P<0.05$ ).

${ }^{1}$ Coeficiente de variação (Coefficient of variation).

dietas foram isoenergéticas, isocálcicas e isoaminoacídicas para lisina, atendendo às exigências nutricionais propostas por Rostagno et al. (2000) para animais nessa faixa etária.

O CDR e o GDP na fase de terminação foram melhores nos animais alimentados com SGUM que naqueles que receberam a ração-referência. Estes resultados corroboram, em parte, os descritos por Engelke et al. (1984), que constataram maior consumo de ração, e por Duduk (1988), que verificou maior ganho de peso. Lima et al. (2003) e Silva (1997) não encontraram diferenças no CDR e GDP de suínos em crescimento e terminação alimentados com ração contendo substituição total do milho seco comum por milho seco com maior teor de óleo.

Lopes et al. (1999), avaliando o uso da silagem de grãos úmidos de milho comum para suínos, relataram melhor digestibilidade deste alimento em relação ao milho grão seco comum. Lima et al. (1998) concluíram que a fermentação anaeróbica, ocorrida durante o processamento da silagem de grãos úmidos de milho, resulta em um produto com maior disponibilidade de energia para suínos que o milho grão seco.

$\mathrm{Na}$ fase de terminação, a CA não diferiu $(\mathrm{P}>0,05)$ entre os tratamentos, como verificado por Engelke et al. (1984), ao trabalharem com silagem de grãos úmidos de milho em substituição do milho seco para suínos em crescimento e terminação, e por Lima et al. (2003), ao alimentarem suínos em crescimento e terminação com ração contendo milho seco com maior teor de óleo em substituição ao milho comum. Lopes et al. (1999) e Duduk (1988), no entanto, verificaram melhora na CA de suínos alimentados com ração contendo silagem de grãos úmidos de milho.

A queda do $\mathrm{pH}$ observada nos tratamentos com silagens (Tabela 6), principalmente para aquele com SGUM, pode ter favorecido o maior ganho de peso na fase de terminação, pois todas as rações continham o mesmo teor de energia. De acordo com Holmes et al. (1974), o aumento da acidez total da dieta de suínos, provocada pela inclusão de milho úmido preservado com ácidos orgânicos, determinou maior tempo de retenção estomacal e fluxo mais homogêneo da digesta para o intestino delgado no intervalo das refeições, favorecendo o processo de digestão. 
Tabela 6 - Valores médios de pH e diâmetro geométrico médio (DGM) das partículas das rações experimentais, do MSe, da SGUM e da $\mathrm{SH}$

Table 6 - $\quad$ pH average values and medium geometric diameter (MDG) of particles of experimental diets and DG, HMCS and RS

\begin{tabular}{|c|c|c|c|c|c|c|c|}
\hline \multirow[t]{3}{*}{$\begin{array}{l}\text { Variável } \\
\text { Variable }\end{array}$} & \multicolumn{4}{|c|}{$\begin{array}{c}\text { Tratamento } \\
\text { Treatment }\end{array}$} & \multicolumn{3}{|c|}{$\begin{array}{l}\text { Alimento } \\
\text { Food }\end{array}$} \\
\hline & $\mathrm{RT}$ & $\mathrm{MSe}^{1}$ & SGUM $^{1}$ & $\mathrm{SH}^{1}$ & $\mathrm{MSe}^{2}$ & SGUM $^{2}$ & $\mathrm{SH}^{2}$ \\
\hline & $C D$ & $D G$ & $H M C S$ & $R S$ & $D G$ & $H M C S$ & $R S$ \\
\hline \multicolumn{8}{|c|}{ Crescimento (Growing) } \\
\hline $\mathrm{pH}$ & 5,64 & 5,80 & 5,06 & 5,11 & 6,09 & 3,98 & 3,96 \\
\hline $\mathrm{DGM}, \mathrm{mm}(M G D, \mathrm{~mm})$ & 702 & 646 & 872 & 761 & 717 & 967 & 900 \\
\hline \multicolumn{8}{|c|}{ Terminação (Finishing) } \\
\hline $\mathrm{pH}$ & 5,66 & 5,75 & 4,71 & 4,77 & 6,09 & 3,98 & 3,96 \\
\hline DGM, mm (MGD, $\mathrm{mm})$ & 698 & 671 & 798 & 745 & 737 & 967 & 900 \\
\hline
\end{tabular}

Os valores de DGM das partículas das rações experimentais contendo silagens foram maiores que daquelas com milho seco. Trabalhando com diversos tamanhos de partículas em rações para leitões, Clements et al. (1975) verificaram tendência em aumentar o tempo de retenção do alimento no estômago quando o tamanho das partículas aumenta. Entretanto, segundo Zanotto et al. (1995), a digestibilidade e o desempenho dos suínos melhoram com a diminuição do DGM das partículas do milho e os melhores resultados ocorrem quando o DGM situa-se entre $500 \mathrm{e}$ $650 \mathrm{~mm}$. Contudo, não foi observado efeito redutor ao desempenho dos animais; pelo contrário, houve maior CDR e GDP para a ração que apresentou maior DGM (SGUM).

Foram observadas diferenças $(\mathrm{P}<0,05)$ entre a raçãoreferência e a ração com silagem de milho reidratado $(\mathrm{SH})$ com maior teor de óleo apenas para a espessura de toucinho e a relação carne:gordura (Tabela 7).

Estes resultados assemelham-se, em parte, aos obtidos por Lima (2003) e Adams \& Jensen (1987), que não encontraram diferenças $(\mathrm{P}>0.05)$ para comprimento de carcaça, área de olho-de-lombo, porcentagem de pernil, espessura de toucinho e relação carne:gordura quando compararam animais alimentados com rações contendo milho seco comum e milho seco com alto teor de óleo.

Nos resultados da análise econômica (Tabela 8), foram considerados o custo da SGUM, de R \$11,34 a saca (60 kg) ensilada e o preço do milho seco comum, $\mathrm{R} \$ 16,20$ a saca, ajustados para a mesma base de $87,45 \%$ de MS.

$\mathrm{O}$ custo da ração por quilograma de peso vivo ganho reduziu $(\mathrm{P}<0,05)$ com a substituição total do milho seco comum por SGUM. O custo por unidade de peso vivo ganho dos animais alimentados com SGUM foi aproximadamente $18 \%$ menor que o dos suínos que receberam milho seco comum na dieta. Rajic \& Sevkovic (1988), citados por Lopes
Tabela 7 - Características de carcaça de suínos no final da fase de terminação, alimentados com rações contendo milho comum e milho com maior teor de óleo nas formas de grão seco e silagens

Table 7 - Carcass traits of swine at the end of finishin fed diets containing common corn, dry grain and silage of higher oil corn

\begin{tabular}{|c|c|c|c|c|c|}
\hline \multirow[b]{2}{*}{$\begin{array}{l}\text { Variável } \\
\text { Variable }\end{array}$} & \multicolumn{4}{|c|}{$\begin{array}{c}\text { Tratamento } \\
\text { Treatment }\end{array}$} & \multirow[b]{2}{*}{$\mathrm{CV}^{1}$} \\
\hline & $\begin{array}{l}\mathrm{RT} \\
C D\end{array}$ & $\begin{array}{l}\mathrm{MSe} \\
D G\end{array}$ & $\begin{array}{l}\text { SGUM } \\
H M C S\end{array}$ & $\begin{array}{l}\mathrm{SH} \\
\mathrm{RS}\end{array}$ & \\
\hline $\begin{array}{l}\text { Peso médio de } \\
\text { abate, } \mathrm{kg} \\
\text { Average weight } \\
\text { slaughter, kg }\end{array}$ & 82,16 & 82,78 & 86,15 & 84,88 & 5,98 \\
\hline $\begin{array}{l}\text { Peso médio de } \\
\text { carcaça, } \mathrm{kg} \\
\text { Average weight } \\
\text { carcass, } \mathrm{kg}\end{array}$ & 64,54 & 65,54 & 68,42 & 68,02 & 6,49 \\
\hline $\begin{array}{l}\text { Rendimento de } \\
\text { carcaça, \% } \\
\text { Carcass yield, \% }\end{array}$ & 78,52 & 79,20 & 79,40 & 80,15 & 1,55 \\
\hline $\begin{array}{l}\text { Peso de pernil, } \mathrm{kg} \\
\text { Ham weight, } \mathrm{kg}\end{array}$ & 10,20 & 10,27 & 10,34 & 10,34 & 7,73 \\
\hline $\begin{array}{l}\text { Rendimento de } \\
\text { pernil, \% } \\
\text { Ham yield, \% }\end{array}$ & 31,57 & 31,34 & 30,21 & 30,40 & 3,51 \\
\hline $\begin{array}{l}\text { Comprimento de } \\
\text { carcaça, cm } \\
\text { Carcass length, } \mathrm{cm}\end{array}$ & 78,05 & 78,31 & 79,84 & 78,84 & 9,73 \\
\hline $\begin{array}{l}\text { Espessura de } \\
\text { toucinho, mm } \\
\text { Back fat thickness, mm }\end{array}$ & $2,27^{b}$ & $2,37^{\mathrm{ab}}$ & $2,46^{\mathrm{ab}}$ & $2,93^{\mathrm{a}}$ & 11,14 \\
\hline $\begin{array}{l}\text { Área de olho-de- } \\
\text { lombo, } \mathrm{cm}^{2} \\
\text { Loin- eye area, } \mathrm{cm}^{2}\end{array}$ & 37,19 & 35,51 & 34,54 & 34,21 & 11,56 \\
\hline $\begin{array}{l}\text { Área de } \\
\text { gordura, } \mathrm{cm}^{2} \\
\text { Fat area, } \mathrm{cm}^{2}\end{array}$ & 14,01 & 15,94 & 16,15 & 19,42 & 15,97 \\
\hline $\begin{array}{l}\text { Relação carne/ } \\
\text { gordura } \\
\text { Meat:fat ratio }\end{array}$ & $0,38^{b}$ & $0,45^{\mathrm{ab}}$ & $0,47^{\mathrm{ab}}$ & $0,57^{\mathrm{a}}$ & 16,94 \\
\hline
\end{tabular}

Médias na mesma linha seguidas por letras distintas são estatisticamente diferentes $(\mathrm{P}<0,05)$ (Means in a row followed by different letter are statistically differ, $P<0.05)$.

${ }^{1}$ Coeficiente de variação (Coefficient of variation). 
Tabela 8 - Custos do quilograma de ração e de ração por quilograma de suíno produzido (CR) e índices de eficiência econômica (IEE) e de custo (IC) para suínos em diferentes períodos experimentais alimentados com as rações contendo milho comum e milho com maior teor de óleo, nas formas de grão seco e silagens

Table 8 - Diet cost per kilogram, cost in diet per kilogram of pig produced $(D C)$, economic efficiency index (EER) and mean cost index (CR) of pigs in different experimental periods fed diets containing common corn, dry grain and silage of higher oil corn

\begin{tabular}{|c|c|c|c|c|c|}
\hline \multirow[b]{2}{*}{$\begin{array}{l}\text { Variável } \\
\text { Variable }\end{array}$} & \multicolumn{4}{|c|}{$\begin{array}{l}\text { Tratamento } \\
\text { Treatment }\end{array}$} & \multirow[b]{2}{*}{$\mathrm{CV}^{1}$} \\
\hline & $\begin{array}{l}\mathrm{R} \mathrm{T} \\
C D\end{array}$ & $\begin{array}{l}\mathrm{MSe} \\
D G\end{array}$ & $\begin{array}{l}\text { SGUM } \\
H M C S\end{array}$ & $\begin{array}{l}\mathrm{SH} \\
\mathrm{RS}\end{array}$ & \\
\hline & & \multicolumn{4}{|c|}{ Crescimento (Growing) } \\
\hline $\begin{array}{l}\text { Custo da ração }{ }^{2}, \mathrm{R} \$ / \mathrm{kg} \\
\text { Diet cost, } R \$ / \mathrm{kg}\end{array}$ & 0,425 & 0,400 & 0,359 & 0,410 & - \\
\hline $\begin{array}{l}\mathrm{CR}^{3}, \mathrm{R} \$ / \mathrm{kg} \text { PV ganho } \\
D C^{3}, R \$ / \mathrm{kg} B W \text { gain }\end{array}$ & $0,95^{\mathrm{a}}$ & $0,93^{\mathrm{a}}$ & $0,79^{\mathrm{b}}$ & $0,91^{\mathrm{a}}$ & 5,22 \\
\hline IEE $E E R$ & 82 & 85 & 100 & 87 & - \\
\hline \multirow[t]{2}{*}{$\mathrm{ICCR}$} & 121 & 118 & 100 & 115 & - \\
\hline & & \multicolumn{4}{|c|}{ Terminação (Finishing) } \\
\hline $\begin{array}{l}\text { Custo da ração }{ }^{2}, \mathrm{R} \$ / \mathrm{kg} \\
\text { Diet cost, } R \$ / \mathrm{kg}\end{array}$ & 0,410 & 0,383 & 0,339 & 0,393 & - \\
\hline $\begin{array}{l}\mathrm{CR}^{3}, \mathrm{R} \$ / \mathrm{kg} \text { PV ganho } \\
D C^{3}, R \$ / \mathrm{kg} B W \text { gain }\end{array}$ & $1,11^{\mathrm{a}}$ & $1,08^{\mathrm{a}}$ & $0,94^{\mathrm{b}}$ & $1,08^{\mathrm{a}}$ & 5,38 \\
\hline $\operatorname{IEE}(E E R)$ & 85 & 87 & 100 & 87 & - \\
\hline IC $(C R)$ & 118 & 114 & 100 & 115 & - \\
\hline
\end{tabular}

1 Coeficiente de variação (Coefficient of variation).

2 Custos baseados em uma relação de preços para a SGUM de $70 \%$ do valor $(\mathrm{R} \$)$ do milho seco comum (Costs based on prices relationship for HMCS of $70 \%$ (R\$) of common corn value)

3 Custo em ração por kg de PV ganho no período; médias na mesma linha seguidas por letras diferentes são estatisticamente diferentes $(P<0,05)$ (Diet cost per kg of BW gain in period, means in a row followed by different letter differ, $P<0.05)$.

(2000), verificaram que a conversão alimentar e o custo por unidade de ganho de peso de suínos nas fases de crescimento e terminação recebendo silagem de grãos úmido de milho comum foram em torno de $25 \%$ menores nos animais alimentados com milho seco.

\section{Conclusões}

O milho com maior teor de óleo nas formas de grão seco, silagem de grãos úmidos e silagem de milho seco reidratado apresentou bons valores nutritivos e conteúdos de energia digestível de $3.587,2.647$ e $2.853 \mathrm{kcal} / \mathrm{kg}$ de matéria natural, respectivamente.

As silagens apresentaram superioridade média de $58 \mathrm{kcal} \mathrm{EM} / \mathrm{kg}$ em relação ao milho seco com maior teor de óleo.

As rações contendo silagem de grãos úmidos proporcionaram menores custos por quilograma de animal produzido e podem substituir totalmente o milho seco comum nas rações para suínos nas fases de crescimento e terminação, sem prejudicar o desempenho.

\section{Literatura Citada}

ADAMS, K.L.; JENSEN, A.H. High-fat-maize in diets for pigs and sows. Animal Feed Science and Technology, v. 17, n.3, p.201-12, 1987

ASSOCIAÇÃO BRASILEIRA DE CRIADORES DE SUÍNOS - ABCS Método Brasileiro de Classificação de Carcaça. Estrela: 1973. 17p (Publicação Técnica, 2).

BELLAVER, C.; FIALHO, ET.; PROTAS, J.F.S. et al. Radícula de malte na alimentação de suínos em crescimento e terminação. Pesquisa Agropecuária Brasileira, v.20, n.8, p.969-974, 1985.

CLEMENTS, E.T.; STEVENS, C.E.; SOUTH WORTH, M. Sites of digesta movement in the gastrintestinal tract of swine. Journal of Nutrition, v.105, p.759-766, 1975.

DUDUK, V. High moisture corn for fattened pigs. Georgicon for Agriculture, v.1, n.1, p.71-78, 1988.

EMBRAPA. CENTRO NACIONAL DE PESQUISA DE SUÍNOS E AVES - CNPSA. Tabela de composição química e valores energéticos de alimentos para suínos e aves. 3.ed. Concórdia: 1991. 97p.

ENGELKE, G.L.; JURGENS, M.H.; SPEER, V.C. Performance of growing-finishing swine fed high-moisture or artificially dried corn in complete and free-choice diets. Journal of Animal Science, v.58, n.6, p.1307-1312, 1984.

GOMES, M.F.M.; BARBOSA, H.P.; FIALHO, E.T. et al. Análise econômica da utilização do triguilho para suínos. (S.I): EMBRAPA - Centro Nacional de Pesquisa de Suínos e Aves, 1991, p.1-2 (Comunicado técnico, 179).

HAN, Y.; PARSONS, C.M. Nutritive value of high oil corn for poultry. Poultry Science, v.66, n.1, p.103-11, 1987.

HOLMES, J.G.; BAYLEY, H.S.; HORNEY, F.D. Digestion and absorption of dry and high-moisture maize diets in the small na large intestine of the pig. British Journal of Nutrition, v.30, n.3, p.401-410, 1973.

HOLMES, J.G.; BAYLEY, H.S.; HORNEY, F.D. Digestion of dry and high-moisture maize diets in stomach of the pig. British Journal of Nutrition, v.32, n.3, p.639-646, 1974

JOBIM, C.C.; CECATO, U.; CANTO, M.W. Utilização da silagem de grãos de cereais na alimentação animal. In: SIMPÓSIO SOBRE PRODUÇÃO E UTILIZAÇÃO DE FORRAGENS CONSERVADAS, 2001, Maringá. Anais... Maringá: Universidade Estadual de Maringá, 2001. p.319.

JOBIM, C.C.; REIS, R.A.; RODRIGUES, L.R.A. et al. Presença de microrganismos na silagem de grãos úmidos de milho ensilados com diferentes proporções de sabugo. Pesquisa Agropecuária Brasileira, v.32, n.2, p.201-204, 1997.

JONGBLOED, A.W.; MROZ, Z.; VAN DER WEIJ- JONGBLOED, R. et al. The effects of microbial phytase, orgnic acids and their interaction in diets for growing pigs. Livestock Production Science, v.67, n.1-2, p.113-122, 2000.

KEPLIN, L.A.S. Silagem de grãos úmidos. 1999. Disponível em: http:// www.correionet.com.br/ fr17/graos.htm. Acesso em: 01/08/2000.

LIMA, G.J.M.M.; SOUZA, O.W.; BELLAVER, C. et al. Determinação da composição química e do valor energético de silagem de milho para suínos. In: CONGRESSO NACIONAL DE MILHO E SORGO, 1998, Recife. Anais... Recife: Associação Brasileira de Milho e Sorgo, 1998. p.277.

LIMA, G.J.M.M.; BELLAVER, C.; COSTA, C.L. et al. Composição química e valor energético para suínos de um milho híbrido de teor de óleo superior. In: CONGRESSO BRASILEIRO DE VETERINÁRIOS ESPECIALISTAS EM SUÍNOS, 10., 2001, Porto Alegre. Anais... Concórdia: EMBRAPA Suínos e Aves, 2001. v.2, p.385.

LIMA, G.J.M.M.; COSTA, C.L.; AVILA, V.S. et al. Efeito do tipo de milho sobre o desempenho, qualidade de carcaça e valorização econômica de suínos em crescimento e terminação. 
In: CONGRESSO BRASILEIRO DE VETERINÁRIOS ESPECIALISTAS EM SUÍNOS, 11., 2003, Goiânia. Anais... Concórdia: EMBRAPA Suínos e Aves, 2003. v.2, p.483.

LOPES, A.B.R.; BERTO, D.A.B.; COSTA, C. et al. Silagem de grãos úmidos de milho para suínos nas fases de crescimento e terminação. In: REUNIÃO ANUAL DA SOCIEDADE BRASILEIRA DE ZOOTECNIA, 36., 1999, Porto Alegre. Anais... São Paulo/Gnosis, [1999] 17 par. CD-ROM. Nutrição de Não-Ruminantes. NUN-114.

LOPES, A.B.R.C. Silagem de grãos úmidos em rações de suínos nas fases inicial, de crescimento e terminação. Botucatu: Universidade Estadual Paulista, 2000. 46p. Dissertação (Mestrado em Zootecnia) - Universidade Estadual Paulista, 2000.

MATTERSON, L.D.; POTTER, L.M.; STUTZ, M.W. et al. The metabolizable energy of feed ingredients for chickens. Research Report, v.7, n.1, p.11-14, 1965.

MOREIRA, I.; ROSTAGNO, H.S.; COELhO, D.T. et al. Determinação dos coeficientes de digestibilidade, valores energéticos e índices de controle de qualidade do milho e soja integral processados pelo calor. Revista da Sociedade Brasileira de Zootecnia, v.23, p.916-929, 1994.

OLIVEIRA, R.P. Utilização da silagem de grãos de milho na alimentação de suínos em fase de creche. Maringá: Universidade Estadual de Maringá, 2002.47p. Dissertação (Mestrado em Zootecnia) - Universidade Estadual de Maringá, 2002.

PEKAS, J.C. Versatile swine laboratory apparatus for physiologic and metabolic studies. Journal of Animal Science, v.27, n.5, p.1303-1309, 1968.

PEREIRA, J.R.A.; ROSSI, J.R.P. Manual prático da avaliação nutricional dos alimentos. Piracicaba: Fundação de Estudos Agrários Luiz de Queiroz, 1995. 25p.

PHILLIP, L.E.; FELLNER, V. Effects of bacterial inoculation of high moisture ear corn on its aerobic stability, digestion and utilization for growth by beef steers. Journal of Animal Science, v.70, p.3178-3187, 1992.

POORE, J.R.; ECK, T.P.; SWINGLE, R.S. et al. Total starch and relative starch availability of grains. In: BIENAL CONFERENCE ON RUMEN FUNCTION, 20., 1989, Chicago. Proceedings... Chicago: 1989. p.35.
ROONEY, L.W.; PFLUGFELDER, R.L. Factors affecting starch digestibility with special emphasis on sorghum and corn. Journal of Animal Science, v.63, p.1607-1623, 1986.

ROSTAGNO, H.S.; ALBINO, L.F.T.; DONZELE, J.L. et al. Tabelas brasileiras para aves e suínos: composição de alimentos e exigências nutricionais. 1.ed. Viçosa, MG: Universidade Federal de Viçosa, 2000. 141p.

UNIVERSIDADE FEDERAL DE VIÇOSA - UFV. SAEG - Sistema de análises estatísticas e genéticas. Versão 7.1., Viçosa, MG: 1997. 150p. (Manual do usuário).

SILVA, D.J.; QUEIROZ, J.S. Análise de alimentos (Métodos químicos e biológicos). 2.ed. Viçosa, MG: Universidade Federal de Viçosa, 2002. 235p.

SILVA, L.P.G. Efeitos da utilização do milho com alto teor de óleo, sobre o desempenho e características das carcaças dos suínos. Jaboticabal: Universidade Estadual de São Paulo, 1997. 118p. Tese (Doutorado em Zootecnia) - Universidade Estadual de São Paulo, 1997.

SOLOMON, T.E. Control of exocrine pancreatic secretion. In: JOHNSON, L.R. et al. (Eds.). Physiology of the gastrointestinal tract. 3.ed. New York: Raven Press, 1994. p. 1499-1529.

ZANOTTO, D.; MOTICELli, C.; MAZZUCO, C. Implicações da granulometria de ingredientes de rações sobre a produção de suínos e aves. In: SIMPÓSIO LATINO-AMERICANO DE NUTRIÇÃO DE SUÍNOS E AVES, 1995, Campinas. Anais... Campinas: Colégio Brasileiro de Nutrição Animal, 1995. p.166.

ZANOTTO, L.D.; BELLAVER, C. Método de determinação da granulometria de ingredientes para o uso em rações de suínos e aves. (S.I): Centro Nacional de Pesquisa de Suínos e Aves - EMBRAPA, 1996. p.15 (Comunicado Técnico, 215). 